\title{
Bronchoscopic features, associations, and outcomes of organizing pneumonia following allogeneic hematopoietic stem cell transplantation
}

\author{
Kyle R. Brownback ${ }^{1,2}$ (D) John W. Frey ${ }^{3} \cdot$ Sunil Abhyankar $^{4}$ \\ Received: 29 November 2018 / Accepted: 15 June 2019 / Published online: 4 July 2019 \\ (C) Springer-Verlag GmbH Germany, part of Springer Nature 2019
}

\begin{abstract}
Organizing pneumonia (OP) is a poorly understood complication of hematopoietic stem cell transplant (HSCT). We identified 15 patients diagnosed with OP following HSCT and described their clinical course. CT chest findings were remarkable for multifocal infiltrates that were predominantly consolidating or ground glass opacities. Bronchoalveolar lavage (BAL) was performed on 14 patients with five having lymphocytosis (>25\% lymphocytes), three with eosinophilia ( $>5 \%$ eosinophils), three with neutrophilia (>30\% neutrophils), and three with normal cell counts. Flow cytometry was analyzed on BAL fluid in 13 patients with 11 having a CD4/CD8 of $\leq 0.9$. Initial treatment with $0.3-1.0 \mathrm{mg} / \mathrm{kg}$ prednisone resulted in improvement in symptoms, in radiographic findings, and in pulmonary function testing for the majority of patients. Six patients had recurrence of OP after completing treatment. Eleven patients had evidence of extra-pulmonary graft-versus-host disease prior to diagnosis of OP, and seven patients were diagnosed with an upper respiratory tract infection (URI) within 8 weeks of OP diagnosis. Most patients respond well to prednisone with significant improvement in pulmonary function, but risk of recurrence is high after cessation of steroid treatment. Risk factors for the development of OP may include prior URI.
\end{abstract}

Keywords Organizing pneumonia $\cdot$ Stem cell transplant $\cdot$ Bronchiolitis obliterans $\cdot$ Pulmonary infiltrate

\section{Introduction}

Advances in the field of allogeneic hematopoietic stem cell transplantation (HSCT) have provided therapies for many people suffering from hematologic malignancies with opportunities for improved long-term survival [1]. Graft-versus-host disease (GVHD) is a multisystem disorder wherein donor immune cells recognize host tissue as foreign and initiate an

Kyle R. Brownback

kbrownback@kumc.edu

1 Division of Pulmonary and Critical Care Medicine, University of Kansas School of Medicine, Kansas City, KS, USA

2 Division of Pulmonary and Critical Care Medicine, University of Kansas Medical Center, 3901 Rainbow BLVD, Mail stop \#3007, Kansas City, KS 66160, USA

3 Department of Internal Medicine, University of Kansas School of Medicine, Kansas City, KS, USA

4 Division of Hematologic Malignancies and Cellular Therapeutics, University of Kansas School of Medicine, Kansas City, KS, USA immune reaction. GVHD is a significant cause of morbidity and mortality following HSCT $[2,3]$. Pulmonary manifestations of GVHD occur in nearly $50 \%$ of patients with GVHD, and are associated with higher rates of late mortality $[4,5]$.

Bronchiolitis obliterans syndrome (BOS), defined as a new onset obstructive pulmonary defect in post-HSCT patients without evidence of infection and at least one extrapulmonary site of chronic GVHD [2], is the most common pulmonary manifestation of chronic GVHD [6]. Another common post-HSCT pulmonary complication is organizing pneumonia (OP), formerly referred to as bronchiolitis obliterans organizing pneumonia, which may be a manifestation of GVHD in some cases. OP is defined as a diffuse interstitial lung disease that typically afflicts the distal respiratory bronchioles and the alveoli with a patchy distribution in which the background lung architecture is preserved [7]. In OP, there is polypoid intraluminal plugs of proliferation of granulation tissue consisting of fibroblasts, myofibroblasts, and loose connective matrix, involving both the alveoli and the alveolar ducts, which can extend to the bronchioles [8]. OP typically presents with non-specific symptoms including cough, 
malaise, low-grade fever, and dyspnea [9]. On chest CT imaging, OP features diffuse, patchy alveolar opacities which may be consolidating or ground-glass in typical cases, though solitary lesions have been described in focal OP [10-12]. OP can feature a restrictive pattern on pulmonary function testing (PFT) or a combined obstructive and restrictive pattern.

OP following HSCT has a reported incidence of between 1 and $10 \%$ patients, with a highly variable time frame from HSCT to development of this condition [13-16]. Potential transplant-related risk factors for development of OP include HLA disparity, peripheral blood stem cell transplantation, and female-to-male HSCT [17]. T cell depletion appears to be protective against the development of both OP and BOS [18]. We sought to review our own cohort of patients diagnosed with post-HSCT OP, with particular interest focused on bronchoscopic findings during the diagnostic workup, potential risk factors for development of OP, and treatment outcomes.

\section{Methods}

Patients were identified from the University of Kansas Medical Center Adult Hematopoietic Stem Cell Transplantation Clinic. All patients had a history of allogeneic HSCT and developed OP following HSCT. Diagnosis of OP was based on clinical features, typical radiographic findings, and exclusion of infectious etiologies or other alternative diagnoses that could be assessed by bronchoscopy or serologic testing $[8,13,17]$. Additionally, all of the patients had persistent symptoms or radiographic changes after completing an appropriate course of empiric broad-spectrum antimicrobials before the diagnosis of $\mathrm{OP}$ was made.

Diagnostic testing performed to exclude infections include standard bacterial and fungal cultures from serum, serum galactomannan antigen, and serum beta-d-glucan assay. From BAL fluid, standard bacterial, fungal, and acid-fast bacterial cultures, galactomannan antigen, Pneumocystis carinii PCR, herpes simplex virus PCR, cytomegalovirus PCR, and grocott stain were all performed. The NxTAG respiratory pathogen panel PCR was also performed on all BAL specimens, and assessed for influenza A, influenza B, respiratory syncytial virus $A$ and $B$, rhinovirus, parainfluenza virus $1-4$, human metapneumovirus, adenovirus, coronavirus, Bordetella pertussis, Chlamydophila pneuomoniae, and Mycoplasma pneumoniae.

Typical symptoms at the time of diagnosis include new onset of respiratory symptoms post-HSCT including cough, dyspnea, or pleurisy. All patients had pulmonary infiltrates on CT imaging of the chest with typical features of OP, including lung consolidation and ground-glass opacities. In all patients, the diagnosis was confirmed by the exclusion of infectious causes, including performing bronchoscopy with bronchoalveolar lavage (BAL) when indicated. Lung biopsy, either bronchoscopically via transbronchial lung biopsy or open surgical lung biopsy, was typically not performed in this patient population due to risks of complications. Following diagnosis of OP, initial follow-up CT scans ranged from 14 to 60 days and then patients typically followed every 30 60 days with a pulmonologist with additional imaging as clinically indicated.

Data collected included background information, HSCT details, other sites of GVHD occurrence, CT findings, symptoms, BAL findings, treatments, and PFT results. Outcomes collected included time until resolution of symptoms, time until resolution of infiltrates, total duration of prednisone treatment, complications, and survival.

All patients were identified from July 1, 2013 until January 1,2018. Censorship of all data occurred on June 30, 2018. The study was performed with the approval of the University of Kansas Medical Center Institutional Review board. $p$ values were determined using ANOVA analysis.

\section{Results}

We identified 15 patients who were diagnosed with OP following HSCT, with a mean age of 48 years (range 24 72 years), 13 of which were males. During this period of time, 716 patients underwent allogeneic HSCT at our institution, giving a prevalence of $2.1 \%$. The patients had various underlying hematologic malignancies, including eight with AML. Ten patients underwent HSCT with unrelated donors. Three patients had a history of underlying lung disease and four patients had a history of tobacco use. Full background characteristics of these patients are described in Table 1.

The mean onset for symptoms was 286 days after transplant. Most patients presented with cough and dyspnea on exertion, but in some, the symptoms also included fever and pleuritic chest pain. Clinical features prior to the diagnosis of OP included history of extra-pulmonary GVHD in 11 of the 15 patients $(73 \%)$, as opposed to an incidence of $59 \%$ in all allogeneic HSCT patients at 1-year-post-HSCT. Seven patients were diagnosed with an upper respiratory tract infection (URI) within 8 weeks of being diagnosed with OP. Twelve patients $(80 \%)$ of patients with OP had received total body irradiation (TBI) during the conditioning regimen. During the same time frame, 716 patients underwent allogeneic HSCT at our institution, and $330(46.1 \%)$ received TBI.

Full details on symptoms, radiographic characteristics, and bronchoscopic findings are shown in Table 2. CT chest findings at the time of diagnosis were remarkable for multifocal infiltrates in all 15 patients. Infiltrates were described as ground glass opacities in six patients, consolidating in two patients, nodular in four patients and a mixed pattern in three patients. At the time of presentation with OP, the patients had 


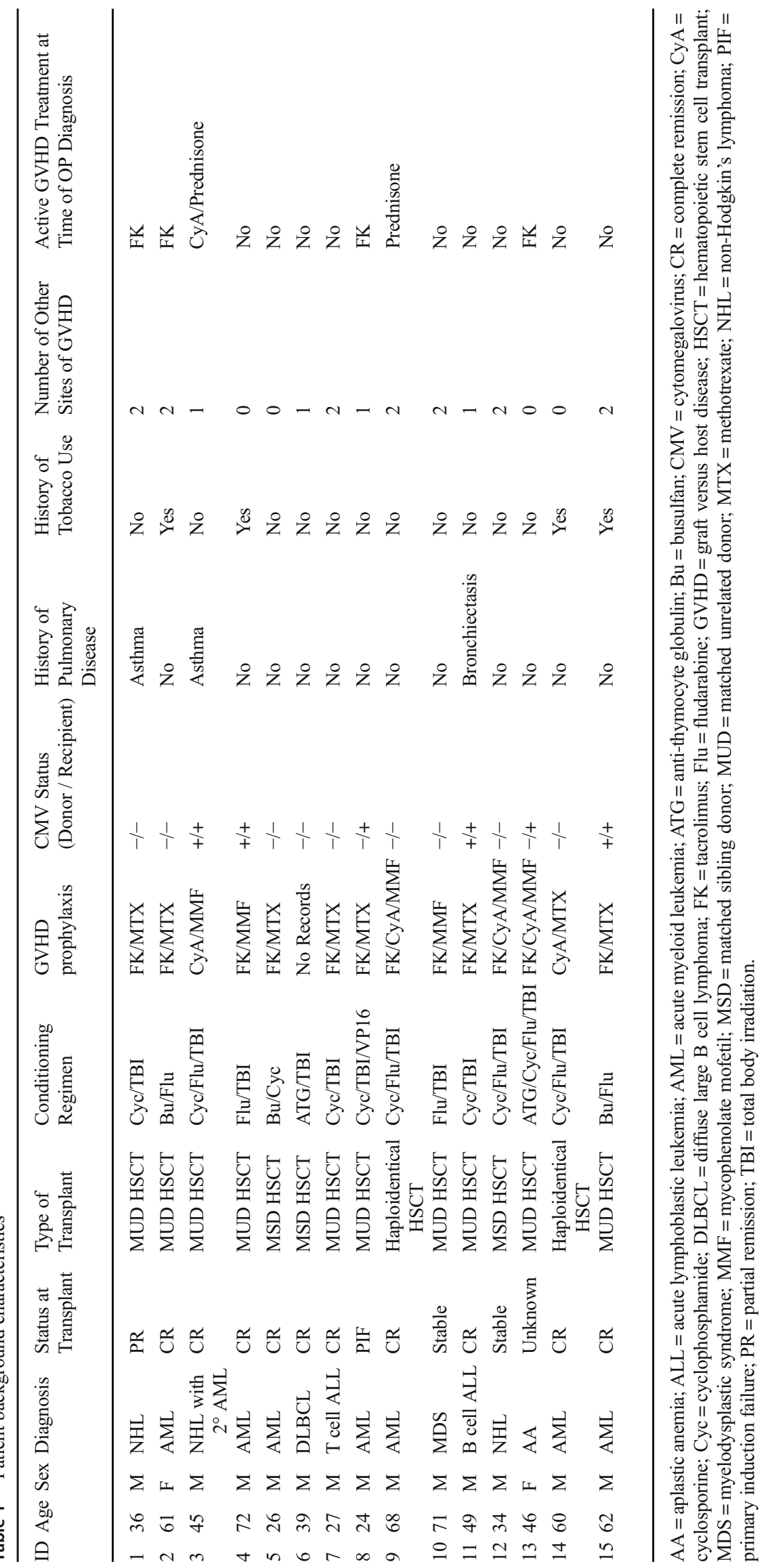




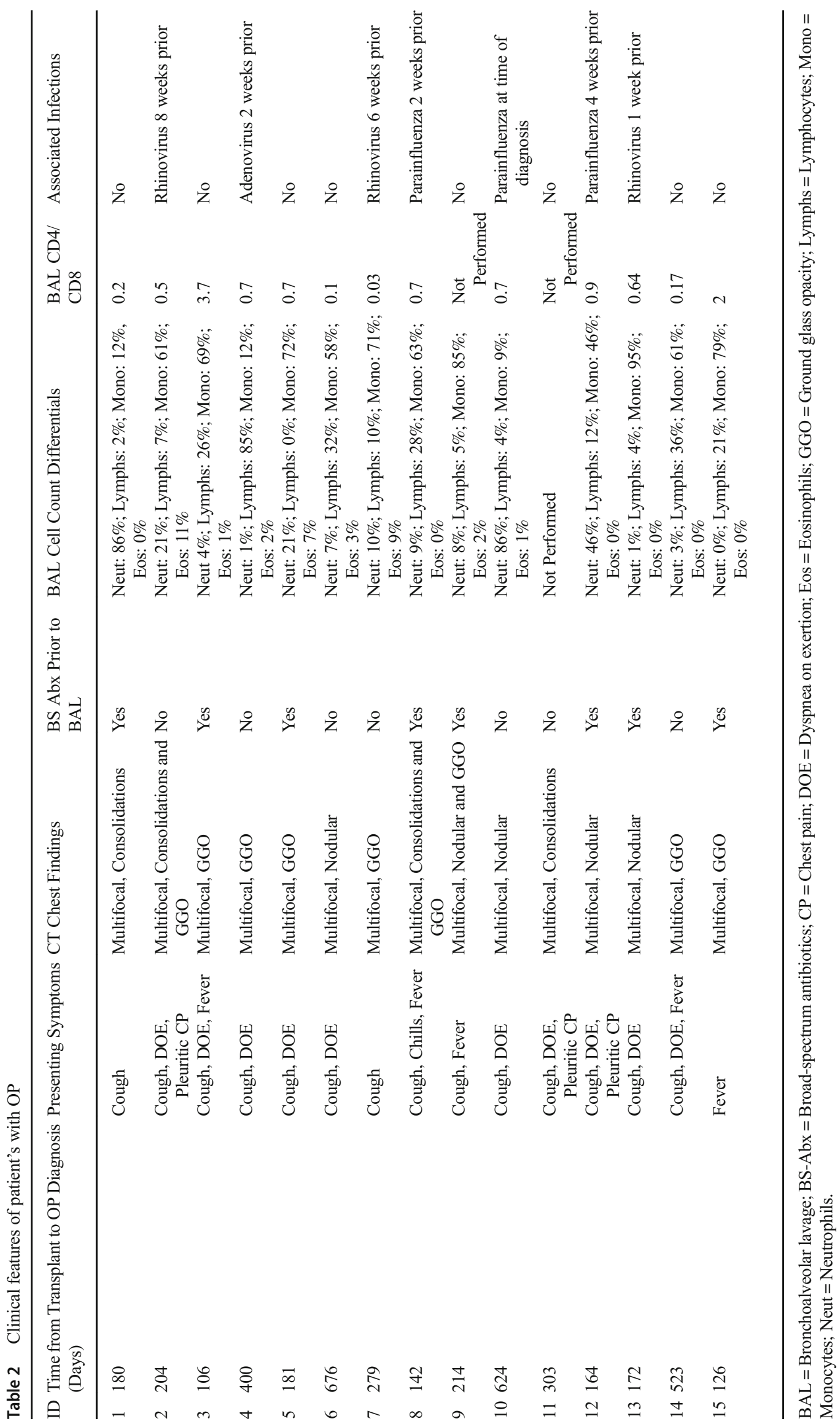




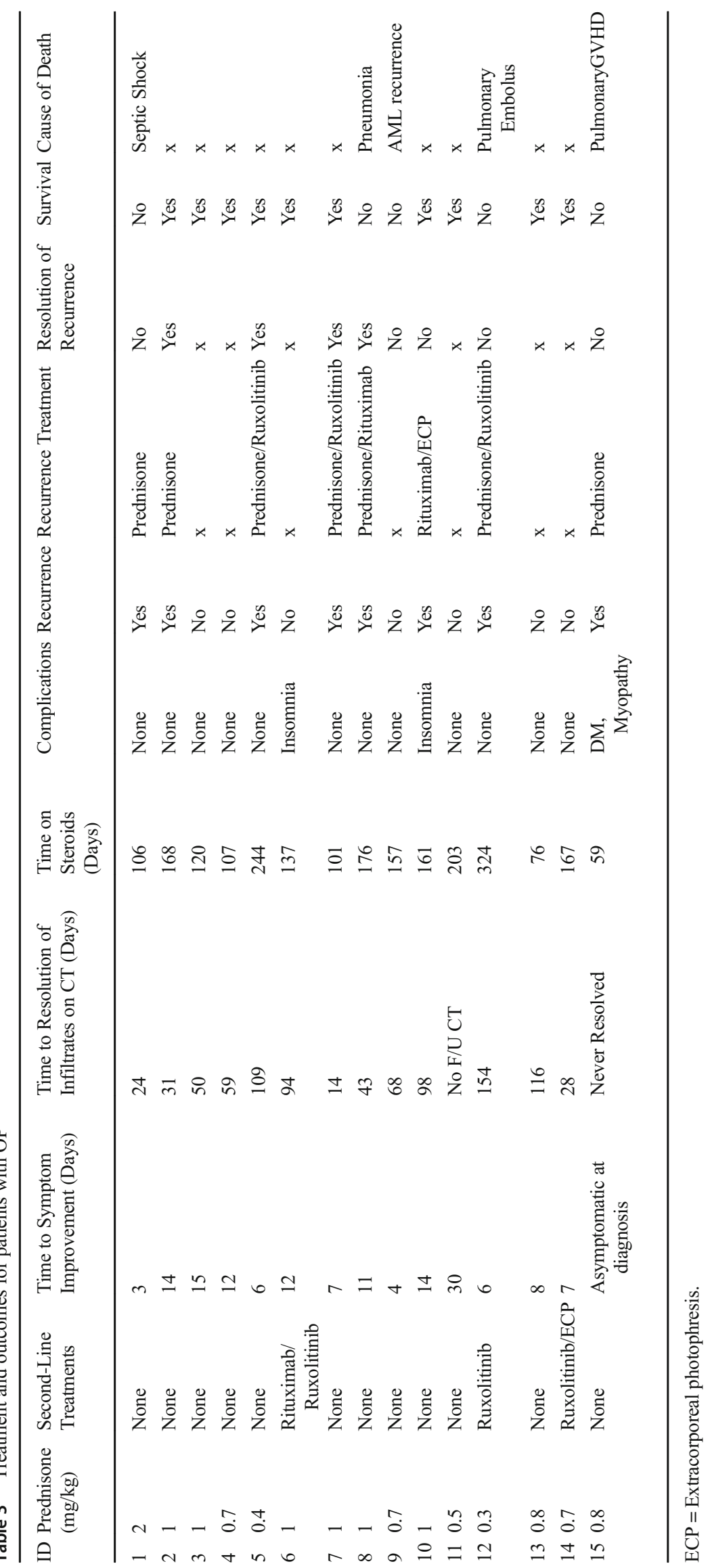


a

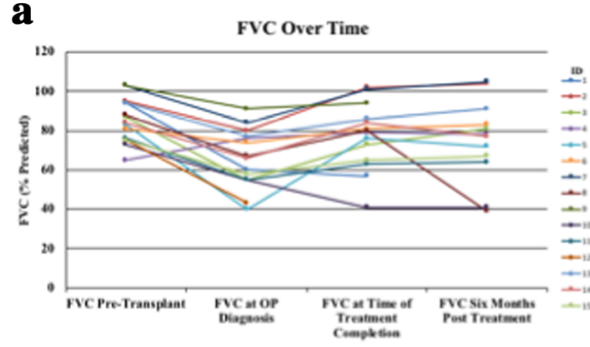

d

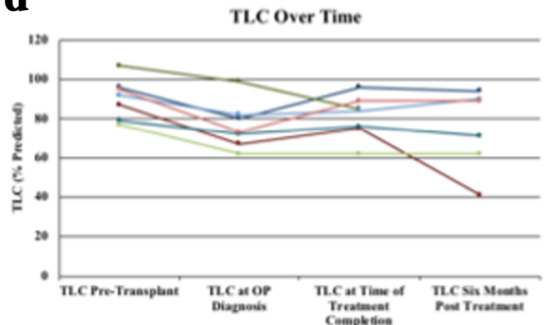

b

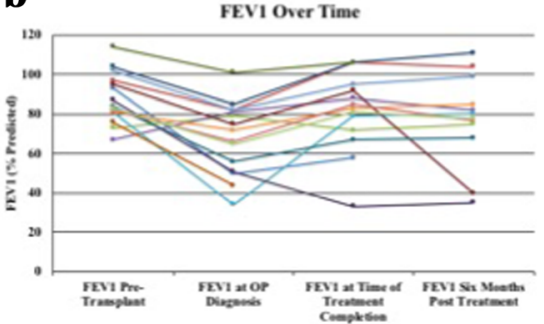

$\mathbf{e}$

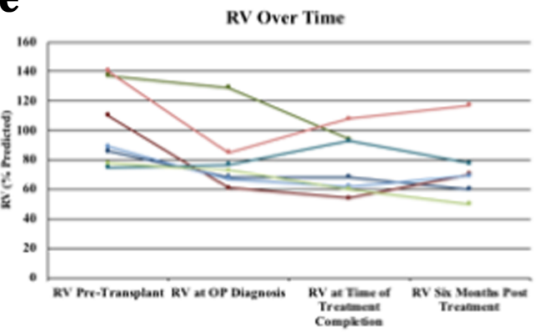

c

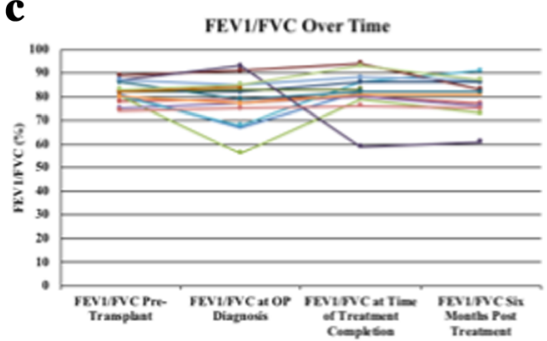

$\mathbf{f}$

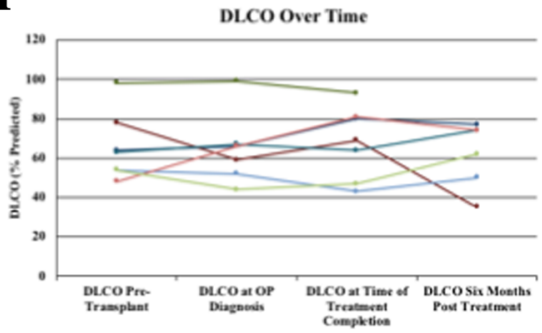

Fig. 1 Dot plot graphs of pulmonary functioning testing (PFT) from pretransplant testing to testing 6-month-post-treatment following OP diagnosis for a forced vital capacity (FVC), $\mathbf{b}$ forced expiratory volume over $1 \mathrm{~s}$ (FEV1), $\mathbf{c}$ FEV1/FVC, d total lung capacity (TLC), e residual volume (RV), and $\mathbf{f}$ diffusion capacity (DLCO). The median time of PFTs at OP

an average reduction in their FVC and FEV1 of $23.1 \%(p$ value $<0.05$ ) and $22.4 \%$ ( $p$ value $<0.05$ ), respectively, when compared to pre-transplant PFT (Fig. 1). Additionally, there was an average reduction in total lung capacity (TLC), residual volume (RV), and diffusion capacity (DLCO) of $13.8 \%$, $18.2 \%$, and $8.3 \%$, respectively.

Bronchoalveolar lavage (BAL) with cell differentials was performed on 14 patients. Five patients featured lymphocytosis ( $>25 \%$ lymphocytes), three with eosinophilia ( $>5 \%$ eosinophils), three with neutrophilia ( $>30 \%$ neutrophils), and three with normal cell counts. Flow cytometry was analyzed on BAL fluid in 13 patients with 11 having a CD4/CD8 of $\leq$ 0.9 .

First-line treatment details for OP is shown in Table 3. The average initial dose of prednisone was $0.86 \mathrm{mg} / \mathrm{kg} /$ day (range $0.3-1.0 \mathrm{mg} / \mathrm{kg} /$ day). Steroid-sparing therapies that were introduced during first-line of treatment included rituximab, ruxolitinib, and rextracorporeal photopheresis (ECP), which were prescribed in three patients.

Treatment outcomes are shown on Table 3. Most patients' symptoms improved with treatment, on average 10.6 days after treatment initiation (range 3-30 days). Follow-up CT scans demonstrated an average time to resolution of infiltrates of 68.3 days (range 14-154 days). There was one patient who did not have resolution of infiltrates with treatment.

In average, patients received steroid treatment for 153.7 days (59-324 days). Complications of steroid treatment included development of insomnia, diabetes, and steroidinduced myopathy. PFTs performed at the time of steroid completion showed an increase in FVC and FEV1 of 18.4\% and $20.7 \%$, respectively, when compared to PFTs completed diagnosis was 204-day-post-transplant (range 106-676 days). The median time of PFTs at steroid completion was 147 days following diagnosis of OP (range 42-244 days) and 332 days at 6-month-post-treatment (range 225-427 days)

at time of OP diagnosis (Fig. 1). Additionally, over this same period of time, TLC, RV, and DLCO had a 5\% increase, no change, and 3\% decrease following treatment with steroids, respectively. PFTs remained stable at 6-month-post-treatment in the majority of patients.

In terms of outcomes, eight patients had recurrence of OP. Of the patients that had recurrence, three were treated with prednisone monotherapy, one of which had resolution. Three patients were treated with a combination of prednisone and ruxolitinib, two of which had resolution. One patient was treated with a combination of prednisone and rituximab and had resolution. The final patient was treated with ECP and rituximab and did not have resolution, though he did have improvement in his PFT and imaging. Five patients ultimately died, with one patient's death attributed to respiratory failure secondary to OP.

\section{Discussion}

We have reviewed our cohort of patients diagnosed with OP following HSCT, and found variability in underlying hematologic process, conditioning regimens, and pre-existing pulmonary disease. The patients presented with similar symptoms, and seven of the 15 patients had a documented viral URI within 8 weeks of OP diagnosis. While there was variability in the cell counts seen on BAL, a CD4/CD8 $\leq 0.9$ was seen in 11 of the 13 patients. We did observe a response to systemic corticosteroids in the majority of patients with improvement in PFTs, though some patients did require second-line therapy. 
Bronchoscopy with BAL is a valuable tool in evaluating pulmonary infiltrates of unknown etiology in the immunosuppressed patient [19]. It is of the utmost importance to exclude infectious etiologies in this patient population, with early bronchoscopy providing higher yield and possibly improving survival [20]. While we found a wide variability in alveolar cell counts identified on BAL, the reduced $\mathrm{CD} 4 / \mathrm{CD} 8$ ratio that we encountered is a known finding in non-HSCTrelated OP [21,22]. Transbronchial lung biopsy was generally avoided in this patient population due to low associated yield and risks of complications [23, 24]. Whereas open lung biopsy is typically recommended to confirm the diagnosis of OP in the non-HSCT population [25], we feel that by excluding infectious etiologies with BAL and narrowing the differential diagnosis substantially, we can expedite treatment and avoid complications of open-lung biopsy, which is declining in its use in HSCT recipients [26].

Our population was treated with corticosteroids as firstline therapy for OP, which is in line with current recommendations $[14,15]$. While the side effect profile of corticosteroids is problematic, their effectiveness in management of OP, both in HSCT recipients and those who have not received HSCT, is accepted as standard of care [15, $25]$. The majority of patients were managed with corticosteroids alone for the initial treatment, though eight of the 15 patients did have recurrence of OP. This begs the questions of how long is the optimal duration of steroid therapy for this entity, and can it be beneficial if extended up to one year [27]?

In patients without history of HSCT, common agents employed in persistent or recurrent OP include cyclophosphamide, macrolides, and rituximab [28-30]. In our population of HSCT recipients, the agents that we employed for recurrent disease included ECP, rituximab, and ruxolitinib, either alone or in combination, with mixed results among the group. These agents have been used successfully in treatment of steroidresistant and steroid-refractory GVHD, including those patients with BOS as a pulmonary manifestation of GVHD [31-35]. Determining the optimal agent to use in recurrent or steroid-resistant OP due to GVHD will require ongoing clinical trials with careful attention to outcomes.

The etiology of post-HSCT OP is unclear at this time. While it is tempting to assume that this is a manifestation of pulmonary GVHD, it is unclear as to why only 11 of our cohort's 15 patients had extra-pulmonary manifestations of GVHD. Previous studies have shown potential associations with the use of irradiation in conditioning regimens [15], which was utilized in 12 of our 15 patients. Another potential cause of $\mathrm{OP}$ in these patients includes previous viral infection, which was documented in seven of the 15 patients. Dysregulated airway inflammation may be the mechanism that explains progression of a URI to OP in the HSCT recipient.
Our study has many limitations. First, this is a retrospective study of a single-center of a rare lung disease following HSCT. Additionally, patients were treated in a non-uniform manner, and the use of steroid-sparing agents was varied among the participants in this study. This variation in treatment choices is largely driven by inequities in drug availability in various patients, often driven by managed care decisions. Unfortunately, this is quite a heterogenous patient population, and many of our limitations are related to the variability in presentation and response to treatment in this inflammatory lung disease. While our population was quite heterogenous, the common link in this population was an exclusion of alternative diagnoses and a generally steroid-responsive disease.

In summary, OP is a condition that may occur following HSCT. It is diagnosed based on characteristic radiographic patterns and the exclusion of infectious etiologies, typically by BAL. Patients may have decline in lung function at the onset of OP, though this is typically reversible with treatment of OP. Corticosteroids remain the standard first-line therapy, though the use of second-line agents is often required in steroid-resistant or recurrent disease.

\section{Compliance with ethical standards}

Local institutional review board gave approval for this study.

Conflict of Interest The authors declare that they have no conflict of interest.

\section{References}

1. Gooley TA, Chien JW, Pergam SA, Hingorani S, Sorror ML, Boeckh M, Martin PJ, Sandmaier BM, Marr KA, Appelbaum FR, Storb R, McDonald GB (2010) Reduced mortality after allogeneic hematopoietic-cell transplantation. N Engl J Med 363(22):20912101

2. Filipovich AH, Weisdorf D, Pavletic S, Socie G, Wingard JR, Lee SJ, Martin P, Chien J, Przepiorka D, Couriel D, Cowen EW, Dinndorf P, Farrell A, Hartzman R, Henslee-Downey J, Jacobsohn D, McDonald G, Mittleman B, Rizzo JD, Robinson M, Schubert M, Schultz K, Shulman H, Turner M, Vogelsang G, Flowers MED (2005) National Institutes of Health consensus development project on criteria for clinical trials in chronic graftversus-host disease: I. diagnosis and staging working group report. Biol Blood Marrow Transplant 11(12):945-956

3. Palmer J, Chai X, Pidala J, Inamoto Y, Martin PJ, Storer B, Pusic I, Flowers MED, Arora M, Pavletic SZ, Lee SJ (2016) Predictors of survival, nonrelapse mortality, and failure-free survival in patients treated for chronic graft-versus-host disease. Blood 127(1):160 166

4. Bhatia S, Francisco L, Carter A, Sun CL, Baker KS, Gurney JG, McGlave PB, Nademanee A, O'Donnell M, Ramsay NKC, Robison LL, Snyder D, Stein A, Forman SJ, Weisdorf DJ (2007) Late mortality after allogeneic hematopoietic cell transplantation and functional status of long-term survivors: report from the bone marrow transplant survivor study. Blood 110(10):3784-3792 
5. Hildebrandt GC, Fazekas T, Lawitschka A, Bertz H, Greinix H, Halter J, Pavletic SZ, Holler E, Wolff D (2011) Diagnosis and treatment of pulmonary chronic GVHD: report from the consensus conference on clinical practice in chronic GVHD. Bone Marrow Transplant 46(10): 1283-1295

6. Au BK, Au MA, Chien JW (2011) Bronchiolitis obliterans syndrome epidemiology after allogeneic hematopoietic cell transplantation. Biol Blood Marrow Transplant 17(7):1072-1078

7. Ryu JH, Myers JL, Swensen SJ (2003) Bronchiolar disorders. Am J Respir Crit Care Med 168(11):1277-1292

8. Cordier JF (2006) Cryptogenic organising pneumonia. Eur Respir J 28(2):422-446

9. Cottin V, Cordier JF (2012) Cryptogenic organizing pneumonia. Semin Respir Crit Care Med 33(5):462-475

10. Cordier JF, Loire R, Brune J (1989) Idiopathic bronchiolitis obliterans organizing pneumonia. Definition of characteristic clinical profiles in a series of 16 patients. Chest 96(5):999-1004

11. Dodd JD, Muller NL (2005) Bronchiolitis obliterans organizing pneumonia after bone marrow transplantation: high-resolution computed tomography findings in 4 patients. J Comput Assist Tomogr 29(4):540-543

12. Mehrian P, Doroudinia A, Rashti A, Aloosh O, Dorudinia A (2017) High-resolution computed tomography findings in chronic eosinophilic vs. cryptogenic organising pneumonia. Int J Tuberc Lung Dis 21(11):1181-1186

13. Afessa B, Litzow MR, Tefferi A (2001) Bronchiolitis obliterans and other late onset non-infectious pulmonary complications in hematopoietic stem cell transplantation. Bone Marrow Transplant 28(5): 425-434

14. Freudenberger TD, Madtes DK, Curtis JR, Cummings P, Storer BE, Hackman RC (2003) Association between acute and chronic graftversus-host disease and bronchiolitis obliterans organizing pneumonia in recipients of hematopoietic stem cell transplants. Blood 102(10):3822-3828

15. Jinta M, Ohashi K, Ohta T, Ieki R, Abe K, Kamata N, Akiyama H, Sakamaki H (2007) Clinical features of allogeneic hematopoietic stem cell transplantation-associated organizing pneumonia. Bone Marrow Transplant 40(5):465-472

16. Yoshihara S, Yanik G, Cooke KR, Mineishi S (2007) Bronchiolitis obliterans syndrome (BOS), bronchiolitis obliterans organizing pneumonia (BOOP), and other late-onset noninfectious pulmonary complications following allogeneic hematopoietic stem cell transplantation. Biol Blood Marrow Transplant 13(7):749-759

17. Nakasone H, Onizuka M, Suzuki N, Fujii N, Taniguchi S, Kakihana K, Ogawa H, Miyamura K, Eto T, Sakamaki H, Yabe H, Morishima Y, Kato K, Suzuki R, Fukuda T (2013) Pre-transplant risk factors for cryptogenic organizing pneumonia/bronchiolitis obliterans organizing pneumonia after hematopoietic cell transplantation. Bone Marrow Transplant 48(10):1317-1323

18. Ditschkowski M, Elmaagacli AH, Trenschel R, Peceny R, Koldehoff M, Schulte C, Beelen DW (2007) T-cell depletion prevents from bronchiolitis obliterans and bronchiolitis obliterans with organizing pneumonia after allogeneic hematopoietic stem cell transplantation with related donors. Haematologica 92(4):558-561

19. Brownback KR, Thomas LA, Simpson SQ (2014) Role of bronchoalveolar lavage in the diagnosis of pulmonary infiltrates in immunocompromised patients. Curr Opin Infect Dis 27(4):322-328

20. Shannon VR, Andersson BS, Lei X, Champlin RE, Kontoyiannis DP (2010) Utility of early versus late fiberoptic bronchoscopy in the evaluation of new pulmonary infiltrates following hematopoietic stem cell transplantation. Bone Marrow Transplant 45(4):647-655
21. Costabel U, Teschler H, Guzman J (1992) Bronchiolitis obliterans organizing pneumonia (BOOP): the cytological and immunocytological profile of bronchoalveolar lavage. Eur Respir J 5(7):791-797

22. Poletti V, Cazzato S, Minicuci N, Zompatori M, Burzi M, Schiattone ML (1996) The diagnostic value of bronchoalveolar lavage and transbronchial lung biopsy in cryptogenic organizing pneumonia. Eur Respir J 9(12):2513-2516

23. Anders GT, Johnson JE, Bush BA, Matthews JI (1988) Transbronchial biopsy without fluoroscopy. A seven-year perspective. Chest 94(3):557-560

24. O'Dwyer DN, Duvall AS, Xia M, Hoffman TC, Bloye KS, Bulte CA, Zhou X, Murray S, Moore BB, Yanik GA (2018) Transbronchial biopsy in the management of pulmonary complications of hematopoietic stem cell transplantation. Bone Marrow Transplant 53(2):193-198

25. Bradley B, Branley HM, Egan JJ, Greaves MS, Hansell DM, Harrison NK et al (2008) Interstitial lung disease guideline: the British Thoracic Society in collaboration with the Thoracic Society of Australia and new Zealand and the Irish thoracic society. Thorax 63(Suppl 5):v1-v58

26. Cheng GS, Stednick ZJ, Madtes DK, Boeckh M, McDonald GB, Pergam SA (2016) Decline in the use of surgical biopsy for diagnosis of pulmonary disease in hematopoietic cell transplantation recipients in an era of improved diagnostics and empirical therapy. Biol Blood Marrow Transplant 22(12):2243-2249

27. Flowers MED, Martin PJ (2015) How we treat chronic graft-versushost disease. Blood 125(4):606-615

28. Davison AG, Heard BE, McAllister WA, Turner-Warwick ME (1983) Cryptogenic organizing pneumonitis. Q J Med 52(207): 382-394

29. Pathak V, Kuhn JM, Durham C, Funkhouser WK, Henke DC (2014) Macrolide use leads to clinical and radiological improvement in patients with cryptogenic organizing pneumonia. Ann Am Thorac Soc 11(1):87-91

30. Shitenberg D, Fruchter O, Fridel L, Kramer MR (2015) Successful rituximab therapy in steroid-resistant, cryptogenic organizing pneumonia: a case series. Respiration 90(2):155-159

31. Brownback KR, Simpson SQ, Pitts LR, Polineni D, McGuirk JP, Ganguly S et al (2016) Effect of extracorporeal photopheresis on lung function decline for severe bronchiolitis obliterans syndrome following allogeneic stem cell transplantation. J Clin Apher 31(4): 347-352

32. Brownback KR, Thomas LA, McGuirk JP, Ganguly S, Streiler C, Abhyankar S (2017) Effect of rituximab on pulmonary function in bronchiolitis obliterans syndrome due to graft-versus-host-disease. Lung 195(6):781-788

33. Kim SJ, Lee JW, Jung CW, Min CK, Cho B, Shin HJ, Chung JS, Kim H, Lee WS, Joo YD, Yang DH, Kook H, Kang HJ, Ahn HS, Yoon SS, Sohn SK, Min YH, Min WS, Park HS, Won JH (2010) Weekly rituximab followed by monthly rituximab treatment for steroid-refractory chronic graft-versus-host disease: results from a prospective, multicenter, phase II study. Haematologica 95(11): 1935-1942

34. Pierelli L, Perseghin P, Marchetti M, Messina C, Perotti C, Mazzoni A, Bacigalupo A, Locatelli F, Carlier P, Bosi A, Società Italiana di Emaferesi and Manipolazione Cellulare (SIdEM), Gruppo Italiano Trapianto Midollo Osseo (GITMO) (2013) Extracorporeal photopheresis for the treatment of acute and chronic graft-versushost disease in adults and children: best practice recommendations from an Italian Society of Hemapheresis and Cell Manipulation 
(SIdEM) and Italian Group for Bone Marrow Transplantation (GITMO) consensus process. Transfusion 53(10):2340-2352

35. Zeiser R, Burchert A, Lengerke C, Verbeek M, Maas-Bauer K, Metzelder SK, Spoerl S, Ditschkowski M, Ecsedi M, Sockel K, Ayuk F, Ajib S, de Fontbrune FS, Na IK, Penter L, Holtick U, Wolf D, Schuler E, Meyer E, Apostolova P, Bertz H, Marks R, Lübbert M, Wäsch R, Scheid C, Stölzel F, Ordemann R, Bug G, Kobbe G, Negrin R, Brune M, Spyridonidis A, Schmitt-Gräff A, van der Velden W, Huls G, Mielke S, Grigoleit GU, Kuball J, Flynn R, Ihorst G, du J, Blazar BR, Arnold R, Kröger N, Passweg J, Halter J, Socié G, Beelen D, Peschel C, Neubauer A, Finke J, Duyster J, von Bubnoff N (2015) Ruxolitinib in corticosteroid-refractory graft-versus-host disease after allogeneic stem cell transplantation: a multicenter survey. Leukemia 29(10):2062-2068

Publisher's note Springer Nature remains neutral with regard to jurisdictional claims in published maps and institutional affiliations. 